$2 \mathrm{MeV}$ electron irradiation effects on the

electrical characteristics of MOS capacitors with

\title{
ALD $\mathrm{Al}_{2} \mathrm{O}_{3}$ dielectrics of different thickness
}

J. M. Rafí ${ }^{1^{*}}$, M.B. González ${ }^{1}$, K. Takakura $^{2}$, I. Tsunoda ${ }^{2}$, M. Yoneoka ${ }^{2}$, O. Beldarrain ${ }^{1}$, M. Zabala ${ }^{1}$, F. Campabadal ${ }^{1}$

${ }^{1}$ Institut de Microelectrònica de Barcelona, IMB-CNM, (CSIC)

Campus UAB, 08193 Bellaterra, Spain

${ }^{2}$ Kumamoto National College of Technology

2659-2 Suya Koshi, Kumamoto 861-1102, Japan

*Corresponding author. Tel.: +34 93 5947700, ext.: 2201

Electronic mail: jm.rafi@csic.es 


\section{ABSTRACT}

The effects of $2 \mathrm{MeV}$ electron irradiation on the electrical characteristics of atomic layer deposited layers of $\mathrm{Al}_{2} \mathrm{O}_{3}$ with different thickness are evaluated by using metal-oxidesemiconductor capacitors with a dielectric physical thickness ranging from $2.8 \mathrm{~nm}$ to 11.6 $\mathrm{nm}$. The capacitance-voltage and current-voltage characteristics of the capacitors are analysed as a function of electron irradiation. A progressive radiation-induced positive charge trapping and increase of the leakage current with electron fluence is observed for the thickest layers subjected to electron irradiation. However, the effects are significantly lower or even negligible for the thinnest $\mathrm{Al}_{2} \mathrm{O}_{3}$ films.

Keywords: $\mathrm{Al}_{2} \mathrm{O}_{3}$; high-k dielectrics; electron irradiation; $\mathrm{ALD}$ 


\section{INTRODUCTION}

In recent years, a number of high permittivity (high-k) dielectrics have been investigated for a wide range of micro/nanoelectronics applications, being $\mathrm{Al}_{2} \mathrm{O}_{3}$ amongst the most studied ones [1,2]. A lot of work has been devoted to physical and electrical characterization, as well as to reliability issues [3]. However, much less is known about their behaviour in radiation environments. The study of ionizing radiation effects on high-k dielectrics is of special interest for space applications, but also for high energy physics experiments and to gain insight into possible effects of advanced micro/nanofabrication processes like e-beam or Xrays lithography. Different works have been published on radiation effects on a limited number of high-k dielectrics, being these mostly limited to irradiations with heavy ions or Xrays, and only separated studies addressing either capacitance-voltage (C-V) or currentvoltage (I-V) characterization have been generally considered $[4,5]$.

In a previous work [6], we studied the effects of $2 \mathrm{MeV}$ electron irradiation on the electrical characteristics of metal-oxide-semiconductor (MOS) capacitors with atomic layer deposited (ALD) films of high-k dielectrics $\left(\mathrm{Al}_{2} \mathrm{O}_{3}, \mathrm{HfO}_{2}\right.$ and a nanolaminate of them) with thickness around $10 \mathrm{~nm}$. The results showed similar radiation-induced charge trapping and interface states generation for the three high-k dielectrics, with an increase of the leakage current with electron irradiation fluence. The aim of the present work is to evaluate the impact of the $\mathrm{Al}_{2} \mathrm{O}_{3}$ high-k dielectric thickness on the radiation effects. 


\section{EXPERIMENTAL}

\subsection{MOS Capacitors}

Square-shaped MOS capacitors with different surface areas (A) were fabricated on (100)oriented Czochralski-grown silicon wafers following a well-established field isolated process [7]. The silicon substrates were p-type (boron-doped), with a resistivity range between 0.1 $\Omega \mathrm{cm}$ and $1.4 \Omega \mathrm{cm}$. For the present work, three different $\mathrm{Al}_{2} \mathrm{O}_{3}$ high-k dielectric layers are studied. The layers were deposited by ALD in a Cambridge NanoTech Savannah 200 system, by using Trimethylaluminium (TMA) and $\mathrm{H}_{2} \mathrm{O}$ as precursors, and $\mathrm{N}_{2}$ as carrier and purge gas. The ALD processes were performed at $200{ }^{\circ} \mathrm{C}$ with 100,50 and 18 cycles. The physical thicknesses (d) of the as-deposited layers were $11.6 \mathrm{~nm}, 5.1 \mathrm{~nm}$ and $2.8 \mathrm{~nm}$, as measured by means of a Rudolph Research Auto EL Ellipsometer, using an index of refraction of 1.64 for the $\mathrm{Al}_{2} \mathrm{O}_{3}$. A $500 \mathrm{~nm}$-thick $\mathrm{Al}(99.5 \%) / \mathrm{Cu}(0.5 \%)$ layer was deposited and patterned by photolithography as the metal gate of the MOS capacitors. Finally, the wafers with $11.6 \mathrm{~nm}$ and $5.1 \mathrm{~nm}$-thick $\mathrm{Al}_{2} \mathrm{O}_{3} \mathrm{MOS}$ capacitors underwent a post-metallization forming gas

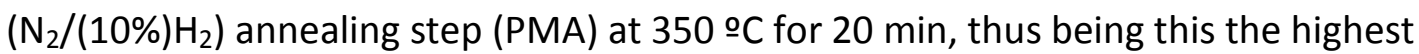
temperature achieved during the dielectric layers processing. On the other hand, the wafer with $2.8 \mathrm{~nm}$-thick $\mathrm{Al}_{2} \mathrm{O}_{3}$ did not receive a PMA, but it was subjected to a post-high-kdeposition thermal anneal at $350 \stackrel{\circ}{ } \mathrm{C}$ for 20 min in $\mathrm{N}_{2}$ ambient.

\subsection{Electrical characterization and irradiation}


In order to evaluate the electrical behaviour of the dielectric layers, C-V and I-V

characteristics were measured in a light-proof and electrically shielded probe station, using an HP-4192 A LF impedance analyzer and an HP 4155B semiconductor parameter analyzer, respectively. If contrary is not indicated, C-V measurements were performed at room temperature on $2.3 \times 10^{-3} \mathrm{~cm}^{2}$ capacitor area structures, while the I-V curves were measured in accumulation conditions on $6.4 \times 10^{-5} \mathrm{~cm}^{2}$ capacitors and at different temperatures ranging from $-40^{\circ} \mathrm{C}$ to $100^{\circ} \mathrm{C}$, using an Espec ETC-200L thermal system.

The $\mathrm{C}-\mathrm{V}$ measurements were performed at $30 \mathrm{kHz}$ signal frequency ( $\mathrm{f}$ ) for both, inversion to accumulation and accumulation to inversion voltage sweeps. The hysteresis was defined as the difference between the extracted flat-band voltages $\left(\mathrm{V}_{\mathrm{fb}}\right)$ corresponding to the two voltage sweeps.

The capacitance of the MOS structure in accumulation regime was assumed as the oxide capacitance $\left(C_{o x}\right)$ and it was used to estimate the capacitance equivalent thickness (CET) of the dielectric layers. The obtained CET values were $5.8 \mathrm{~nm}, 3.5 \mathrm{~nm}$ and $2.3 \mathrm{~nm}$, respectively. The effective trapped charge density $\left(\mathrm{N}_{\text {eff }}\right)$, defined as a charge located at the insulator/silicon interface, was obtained from the comparison of the extracted $V_{\mathrm{fb}}$ values with the ones expected for an ideal MOS structure with $4.25 \mathrm{eV}$ metal work function, corresponding to the aluminium gate electrode, following eq. (1):

$$
N_{e f f}=\frac{C_{o x}}{q A} \cdot\left(\phi_{m s}-V_{f b}\right)
$$


where $\phi_{\mathrm{ms}}$ is the metal-semiconductor work function difference, and $\mathrm{q}$ is the electron charge.

The conductance versus voltage (G-V) characteristics were also recorded. An estimation of the interface states density $\left(D_{i t}\right)$ was obtained from the peak of the parallel conductance $\left(G_{p}\right)$ derived from the $G-V$ measurements [8]:

$$
D_{i t} \approx \frac{2.5}{q \cdot A} \cdot \frac{G_{p}}{2 \pi f}
$$

with:

$$
G_{p}=\frac{G}{\left(\frac{G}{2 \pi f C_{o x}}\right)^{2}+\left(1-\frac{C}{C_{o x}}\right)^{2}}
$$

Unbiased $2 \mathrm{MeV}$ electron irradiations were performed at room temperature for three different fluences $\left(\phi=1 \times 10^{14} \mathrm{e} / \mathrm{cm}^{2}, 1 \times 10^{15} \mathrm{e} / \mathrm{cm}^{2}\right.$ and $1 \times 10^{16} \mathrm{e} / \mathrm{cm}^{2}$, with total ionizing doses about 2.5 Mrad (Si), $25 \mathrm{Mrad}(\mathrm{Si})$ and $250 \mathrm{Mrad}$ (Si), respectively) using the electron accelerator at Takasaki-JAEA in Japan.

\section{Results and discussion}

\subsection{Capacitance-voltage characteristics}


Fig. 1 shows the C-V characteristics measured from inversion to accumulation of nonirradiated and $10^{16} \mathrm{e} / \mathrm{cm}^{2}$ irradiated $\mathrm{Al}_{2} \mathrm{O}_{3} \mathrm{MOS}$ capacitors. A negative shift of the characteristics is observed with electron irradiation, indicating positive charge build-up for all the irradiated high-k dielectric layers. However, a significant dependence of the radiation effects on the $\mathrm{Al}_{2} \mathrm{O}_{3}$ thickness is noticed. While $\mathrm{V}_{\mathrm{fb}}$ shifts of more than $1 \mathrm{~V}$ are observed for the $11.6 \mathrm{~nm} \mathrm{Al}_{2} \mathrm{O}_{3}$ layers, this is less than one tenth for the case of the thinnest $2.8 \mathrm{~nm}$ films and intermediate shifts of about $0.7 \mathrm{~V}$ are detected for the $5.1 \mathrm{~nm}$ capacitors.

With regard to C-V curves hysteresis, small values (below 30 or $50 \mathrm{mV}$ ) are observed for the non-irradiated samples of the different $\mathrm{Al}_{2} \mathrm{O}_{3}$ thicknesses studied. However, in agreement with our previous study on irradiated thick high-k dielectric layers [6], the hysteresis is found to increase with electron irradiation fluence for the $11.6 \mathrm{~nm}$ samples, reaching values in the range of $300 \mathrm{mV}$ for the highest irradiation fluence $\left(10^{16} \mathrm{e} / \mathrm{cm}^{2}\right)$. On the other hand, only a slight hysteresis increase with irradiation, in the range of $20 \mathrm{mV}$, has been registered for the MOS capacitors with $2.8 \mathrm{~nm} \mathrm{Al}_{2} \mathrm{O}_{3}$.

Fig. 2 shows the effective trapped charge densities ( $\left.N_{\text {eff }}\right)$ extracted for non-irradiated and 2 MeV electron-irradiated $\mathrm{Al}_{2} \mathrm{O}_{3} \mathrm{MOS}$ capacitors. Before irradiation, negative oxide charge is detected in the $\mathrm{Al}_{2} \mathrm{O}_{3}$, in agreement with previous works $[6,7]$. The results indicate similar radiation-induced positive charge trapping for the thickest layers (10 $\mathrm{nm}$ and $5.1 \mathrm{~nm}$ ), but, only slight $\mathrm{N}_{\text {eff }}$ changes are observed for the thinnest $2.8 \mathrm{~nm}$ films. It is important to note that the radiation-induced positive charge generation in the thickest $\mathrm{Al}_{2} \mathrm{O}_{3}$ layers leads to positive $\mathrm{N}_{\text {eff }}$ values for the more irradiated samples. 
Although, to our best knowledge, no results about comparable $\mathrm{Al}_{2} \mathrm{O}_{3}$ dielectric layers subjected to electron irradiation have been published in the literature, a similar radiationinduced charge trapping trend has been obtained for the case of $\mathrm{Al}_{2} \mathrm{O}_{3}$ and $\mathrm{HfO}_{2}$ ALD layers of similar thicknesses exposed to comparable high irradiation doses (1-10 $\left.\mathrm{Mrad}\left(\mathrm{SiO}_{2}\right)\right)$ with $10 \mathrm{keV}$ X-rays $[4,9,10]$. Furthermore, good radiation hardness was also observed there for thin (2-3 nm) $\mathrm{Al}_{2} \mathrm{O}_{3}$ layers.

Fig. 3 shows the extracted interface states densities $\left(D_{i t}\right)$. A progressive increase of $D_{i t}$ with electron irradiation is observed for the $5.1 \mathrm{~nm}$ and $11.6 \mathrm{~nm} \mathrm{Al}_{2} \mathrm{O}_{3}$ capacitors. This is in agreement with our previous work on irradiated MOS devices with thick high-k dielectric films [6]. On the other hand, no significant radiation-induced $D_{i t}$ increase is observed for the less-irradiated $2.8 \mathrm{~nm}$ layers, which did not receive a post-metallization anneal (PMA) and show higher initial $D_{i t}$ values. It is only after the highest electron irradiation fluence that the radiation-induced $D_{i t}$ increase can be noticed in these samples. The effect of a PMA treatment is known to decrease the density of negative effective trapped charges, as well as to significantly reduce C-V hysteresis and interface states density (Fig. 3 inset) [11]. Furthermore, a PMA has also been found to significantly reduce any possible wafer level variability of $C-V$ and I-V characteristics. $D_{\text {it }}$ values around $5 \times 10^{10} \mathrm{~cm}^{-2} \cdot \mathrm{eV}^{-1}$ were typically measured on non-irradiated $2.8 \mathrm{~nm}$ samples which underwent a PMA.

About interface state generation as a function of irradiation, only few results have been published for comparable high-k dielectric layers. Some were obtained by means of charge pumping measurements on similar $\mathrm{Al}_{2} \mathrm{O}_{3} \mathrm{ALD}$ films subjected to $10-\mathrm{keV} \mathrm{X}$-rays irradiation 
[9]. A decrease of interface states density after irradiation was observed there, which was attributed to radiation-induced neutralization of traps in those layers with quite high preirradiation interface states densities (in the range of $10^{12} \mathrm{~cm}^{-2}$ ). In our case, as in the results generally obtained for $\mathrm{Si} / \mathrm{SiO}_{2}$ systems [12], $\mathrm{D}_{\text {it }}$ is found to increase with electron irradiation fluence, and even a similar potential law $\left(\Delta D_{\text {it }} \propto \phi^{n}\right.$, with $n$ around $\left.2 / 3\right)$ has been inferred for the case of the thicker $\mathrm{Al}_{2} \mathrm{O}_{3}$ layers [6].

Similarly to what happens for $D_{\text {it }}$ in Fig. 3, for the less irradiated $2.8 \mathrm{~nm}$ samples of Fig. 2 , the radiation-induced increase of $\mathrm{N}_{\text {eff }}$ may be partly influenced by the fact that these samples did not receive a PMA. However, the data corresponding to non-irradiated $2.8 \mathrm{~nm}$ samples which underwent a forming gas anneal (solid symbols in Figs. 1 and 2) should provide an idea of the magnitude of this phenomenon. This behaviour has been further corroborated by $5 \mathrm{~nm}$ samples which were not exposed to PMA and also showed masked $D_{\text {it }}$ and $N_{\text {eff }}$ radiation-induced degradation for low electron fluences (not shown here for simplicity). Finally, a similar increased radiation hardness in $7.5 \mathrm{~nm}$-thick ALD $\mathrm{HfO}_{2}$ exposed up to 10 $\operatorname{Mrad}\left(\mathrm{SiO}_{2}\right)$ with X-rays has been indeed reported for MOS capacitors which did not receive a forming gas anneal [4]. This has been attributed to a possible charge compensation effect in those thicker $\mathrm{HfO}_{2}$ layers which showed significant C-V hysteresis [10].

\subsection{Current-voltage characteristics}

Fig. 4 shows the current density (I/A) versus applied voltage measured at $20^{\circ} \mathrm{C}$ for nonirradiated and irradiated MOS capacitors at different fluences. The obtained results show a 
significant increase of the current density through the oxide layers with electron irradiation, thus indicating a radiation-induced degradation of the dielectric properties. Moreover, an important dependence of the radiation effects on the $\mathrm{Al}_{2} \mathrm{O}_{3}$ thickness is also noticed from the I-V curves, which shift towards more positive values, due to positive charge trapping and defect generation. While I-V voltage shifts of nearly $3 \mathrm{~V}$ at $10^{-7} \mathrm{~A} / \mathrm{cm}^{2}$ current density are observed after irradiation for the thickest layers, the changes are hard to detect for the case of the thinnest $2.8 \mathrm{~nm}$ films and intermediate shifts of about $1 \mathrm{~V}$ are noticed for the $5.1 \mathrm{~nm}$ capacitors.

It is known from $\mathrm{SiO}_{2}$ gate dielectrics that radiation-induced defects can be detrapped or annealed by tunnel or thermal emission processes [13]. For the thickest $\mathrm{Al}_{2} \mathrm{O}_{3}$ irradiated layers, a good stability of the damage was confirmed by measurements carried out after some months of storage at room temperature conditions. The results of some I-V measurements carried out after 6 months of the irradiations are also given in Figure 4 for the case of the highest irradiation fluences $\left(10^{16} \mathrm{e} / \mathrm{cm}^{2}\right)$. Note that for the re-measured samples the irradiated pieces of wafers had also been subjected during about 90 minutes to each one of the five different temperatures ranging from $-40 \circ \mathrm{C}$ to $100 \circ \mathrm{C}$ used for the initial post-irradiation characterization.

With regard to measurement temperature, this has been found to have a significant impact on the I-V characteristics of the thickest layers. On the other hand, this appears negligible for the thinnest $2.8 \mathrm{~nm}$ films (Fig. 5). The study of the conduction mechanisms through the thickest (11.6 nm) $\mathrm{Al}_{2} \mathrm{O}_{3}$ layers has shown that Poole-Frenkel (PF) may play a dominant role in the lower electric field region of the characteristics $\left(<\sim 2 \times 10^{6} \mathrm{~V} / \mathrm{cm}\right.$ in Fig. 5(a)) [6]. The 
inset in Fig. 5(a) shows the extracted PF trap energy levels, which are found to decrease as a function of electron irradiation fluence. This could be originated by radiation-induced defects. On the other hand, for the high field region $\left(>\sim 3 \times 10^{6} \mathrm{~V} / \mathrm{cm}\right.$ in Fig. $\left.5(\mathrm{a})\right)$, reasonable Fowler-Nordheim (FN) tunnelling barrier height values of about $2.6 \mathrm{eV}$ have been extracted for the non-irradiated $11.6 \mathrm{~nm} \mathrm{Al}{ }_{2} \mathrm{O}_{3}$ samples, by assuming the effective mass of electrons in alumina as 0.2 times the free electron mass [6]. Concerning the thinnest $\mathrm{Al}_{2} \mathrm{O}_{3}$ layers, the weak temperature dependence may suggest direct and FN tunnelling mechanisms to play a dominant role in the low and high field regions of the $2.8 \mathrm{~nm}$ samples, respectively, and PF may still have some contribution in the low field region of the $5.1 \mathrm{~nm}$ films.

\section{Conclusions}

The effects of $2 \mathrm{MeV}$ electron irradiation on the C-V and I-V characteristics of MOS capacitors with $\mathrm{Al}_{2} \mathrm{O}_{3}$ high-k layers with different dielectric thicknesses have been evaluated. Before irradiation, negative effective charges are observed for the $\mathrm{Al}_{2} \mathrm{O}_{3}$ layers. However, the results show a progressive increase of positive charges with increasing electron fluence for the thickest $\mathrm{Al}_{2} \mathrm{O}_{3}$ layers, giving rise to positive effective charges in the dielectric for the more irradiated samples. The results show a significant reduction of the radiation-induced damage for the thinnest $\mathrm{Al}_{2} \mathrm{O}_{3}$ dielectric layers.

\section{Acknowledgements}


This work has been partially funded by the Spanish Ministry of Science and Innovation through project TEC2011-27292-C02-02, the AGAUR of the Generalitat de Catalunya under contract 2009SGR228 and by Inter-University Laboratory for the Joint Use of the JAEA irradiation facilities in Japan. 


\section{References}

[1] H. Wong, H. Iwai, On the scaling issues and high-k replacement of ultrathin gate dielectrics for nanoscale MOS transistors, Microelectron Eng 83 (2006) 1867-1904.

[2] J. Robertson, High dielectric constant gate oxides for metal oxide Si transistors, Rep Prog Phys 69 (2006) 327-396.

[3] G. Ribes, J. Mitard, M. Denais, S. Bruyere, F. Monsieur, C. Parthasarathy, E. Vincent, G. Ghibaudo, Review on high-k dielectrics reliability issues, IEEE T Device Mat Re 5 (2005) 5-19.

[4] J.A. Felix, J.R. Schwank, D.M. Fleetwood, M.R. Shaneyfelt, E.P. Gusev, Effects of radiation and charge trapping on the reliability of high-k gate dielectrics, Microelectron Reliab 44 (2004) 563-575.

[5] B.K. Choi, D.M. Fleetwood, L.W. Massengill, R.D. Schrimpf, K.F. Galloway, M.R. Shaneyfelt, T.L. Meisenheimer, P.E. Dodd, J.R. Schwank, Y.M. Lee, R.S. Johnson, G. Lucovsky, Reliability degradation of ultra-thin oxynitride and $\mathrm{Al}_{2} \mathrm{O}_{3}$ gate dielectric films owing to heavy-ion irradiation, Electron Lett 38 (2002) 157-158.

[6] J.M. Rafí, F. Campabadal, H. Ohyama, K. Takakura, I. Tsunoda, M. Zabala, O. Beldarrain, M.B. González, H. García, H. Castán, A. Gómez, S. Dueñas, 2 MeV electron irradiation effects on the electrical characteristics of metal-oxide-silicon capacitors with atomic layer deposited $\mathrm{Al}_{2} \mathrm{O}_{3}, \mathrm{HfO}_{2}$ and nanolaminated dielectrics, Solid-State Electron 79 (2013) 65-74.

[7] F. Campabadal, J.M. Rafí, M. Zabala, O. Beldarrain, A. Faigón, H. Castán, A. Gómez, H. García, S. Dueñas, Electrical characteristics of metal-insulator-semiconductor 
structures with atomic layer deposited $\mathrm{Al}_{2} \mathrm{O}_{3}, \mathrm{HfO}_{2}$, and nanolaminates on different silicon substrates, J Vac Sci Technol B 29 (2011) 01AA07.

[8] Y. Hwang, R. Engel-Herbert, N.G. Rudawski, S. Stemmer, Analysis of trap state densities at $\mathrm{HfO}_{2} / \mathrm{In}_{0.53} \mathrm{Ga}_{0.47}$ As interfaces, Appl Phys Lett 96 (2010) 102910.

[9] J.A. Felix, M.R. Shaneyfelt, D.M. Fleetwood, T.L. Meisenheimer, J.R. Schwank, R.D. Schrimpf, P.E. Dodd, E.P. Gusev, C. D'Emic, Radiation-induced charge trapping in thin $\mathrm{Al}_{2} \mathrm{O}_{3} / \mathrm{SiO}_{\mathrm{x}} \mathrm{N}_{\mathrm{y}} / \mathrm{Si}(100)$ gate dielectric stacks, IEEE T Nucl Sci 50 (2003) 1910-1918.

[10] J.A. Felix, M.R. Shaneyfelt, J.R. Schwank, P.E. Dodd, D.M. Fleetwood, X.J. Zhou, E.P. Gusev, The effects of radiation and charge trapping on the reliability of alternative gate dielectrics, In: E. Gusev (Ed.), Proceedings of the NATO advanced research workshop on defects in advanced high-k dielectric nano-electronic semiconductor devices, St. Petersburg, Russia, 2005. pp. 299-321.

[11] F. Campabadal, O. Beldarrain, M. Zabala, M.C. Acero, J.M. Rafí, Comparison between $\mathrm{Al}_{2} \mathrm{O}_{3}$ thin films grown by ALD using $\mathrm{H}_{2} \mathrm{O}$ or $\mathrm{O}_{3}$ as oxidant source, In: Proceedings of the 2011 Spanish conference on electron devices (CDE), Palma de Mallorca, Spain; 2011. DOI: 10.1109/SCED.2011.5744238.

[12] J.R. Srour, J.M. McGarrity, Radiation Effects on Microelectronics in Space, P IEEE 76 (1988) 1443-1469.

[13] T.R. Oldham, F.B. McLean, Total ionizing dose effects in MOS oxides and devices, IEEE T Nucl Sci 50 (2003) 483-499. 


\section{FIGURE CAPTIONS}

Figure 1: C-V characteristics measured for non-irradiated and $10^{16} \mathrm{e} / \mathrm{cm}^{2}$ irradiated $\mathrm{Al}_{2} \mathrm{O}_{3} \mathrm{MOS}$ capacitors with three different dielectric thicknesses. The curve with solid triangle symbols corresponds to a non-irradiated $2.8 \mathrm{~nm}$ sample which underwent a post-metallization anneal (PMA).

Figure 2: Extracted effective trapped charge densities $\left(\mathrm{N}_{\text {eff }}\right)$ for non-irradiated and 2 MeV electron-irradiated $\mathrm{Al}_{2} \mathrm{O}_{3}$ MOS capacitors with different dielectric thicknesses. The solid triangle symbol corresponds to a non-irradiated $2.8 \mathrm{~nm}$ sample which underwent a post-metallization anneal (PMA).

Figure 3: Extracted interface states densities $\left(D_{i t}\right)$ for non-irradiated and $2 \mathrm{MeV}$ electron-irradiated MOS capacitors with 3 different $\mathrm{Al}_{2} \mathrm{O}_{3}$ dielectric thicknesses. The inset shows the impact of PMA lowering the peak of the conductance measured at $100 \mathrm{kHz}$ in non-irradiated $5.1 \mathrm{~nm}$-thick $\mathrm{Al}_{2} \mathrm{O}_{3} \mathrm{MOS}$ capacitors. 
Figure 4: Current density versus applied gate voltage measured at $20^{\circ} \mathrm{C}$ for nonirradiated and irradiated $\mathrm{Al}_{2} \mathrm{O}_{3}$ MOS capacitors with (a) $11.6 \mathrm{~nm}$, (b) $5.1 \mathrm{~nm}$ and (c) $2.8 \mathrm{~nm}$ dielectric thickness. The results of some I-V measurements carried out after 6 months of the irradiations and after having subjected the irradiated pieces of wafers to the initial characterization at different temperatures are also given for $10^{16} \mathrm{e} / \mathrm{cm}^{2}$ irradiation fluence.

Figure 5: Current density versus electric field for irradiated $\mathrm{Al}_{2} \mathrm{O}_{3} \mathrm{MOS}$ capacitors with (a) $11.6 \mathrm{~nm}$, (b) $5.1 \mathrm{~nm}$ and (c) $2.8 \mathrm{~nm}$ dielectric thickness measured at different temperatures. $V_{\mathrm{fb}}$ was extracted from room- $\mathrm{T} C-\mathrm{V}$ measurements and corrected for temperature dependence. 


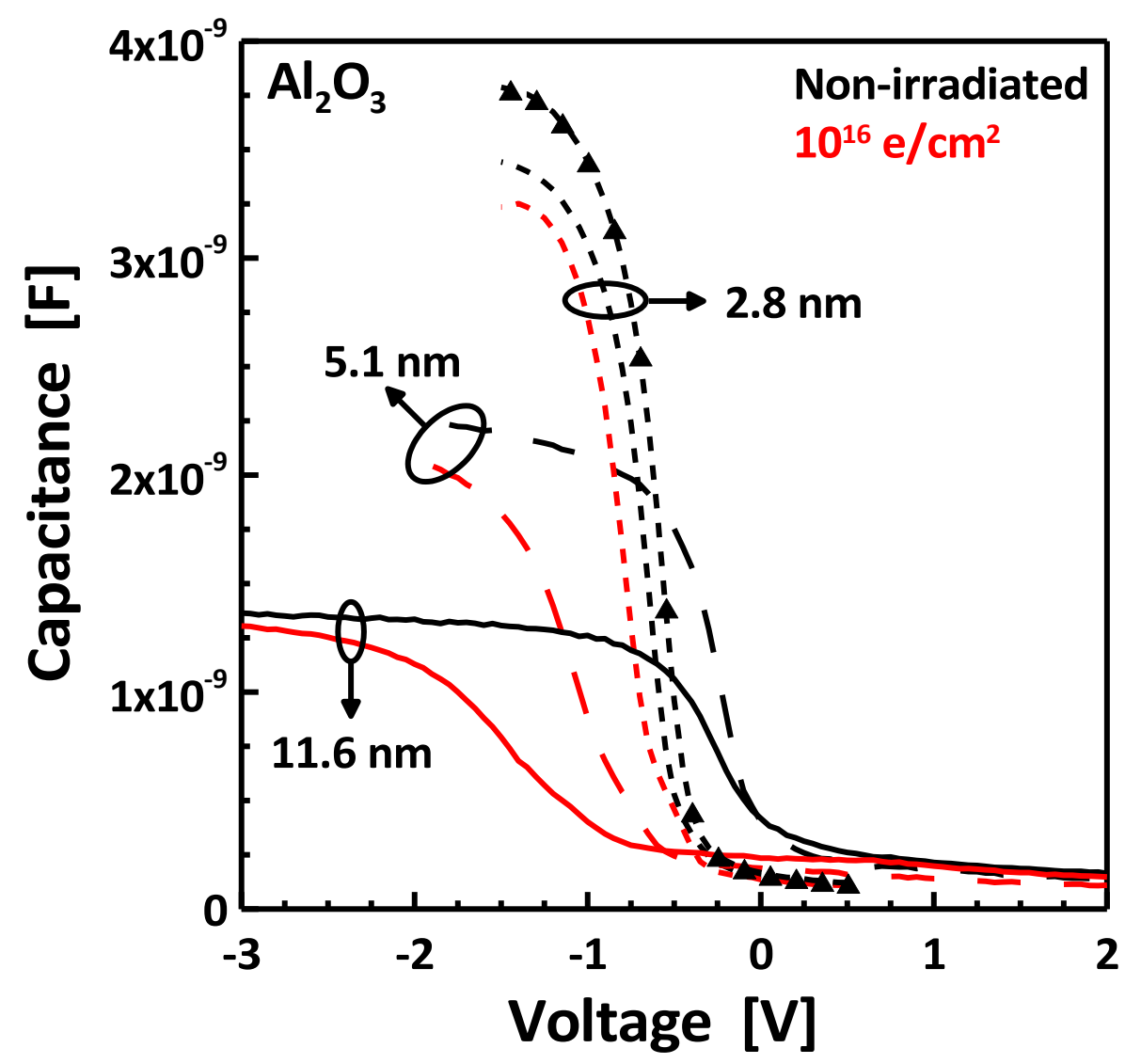

Figure 1 


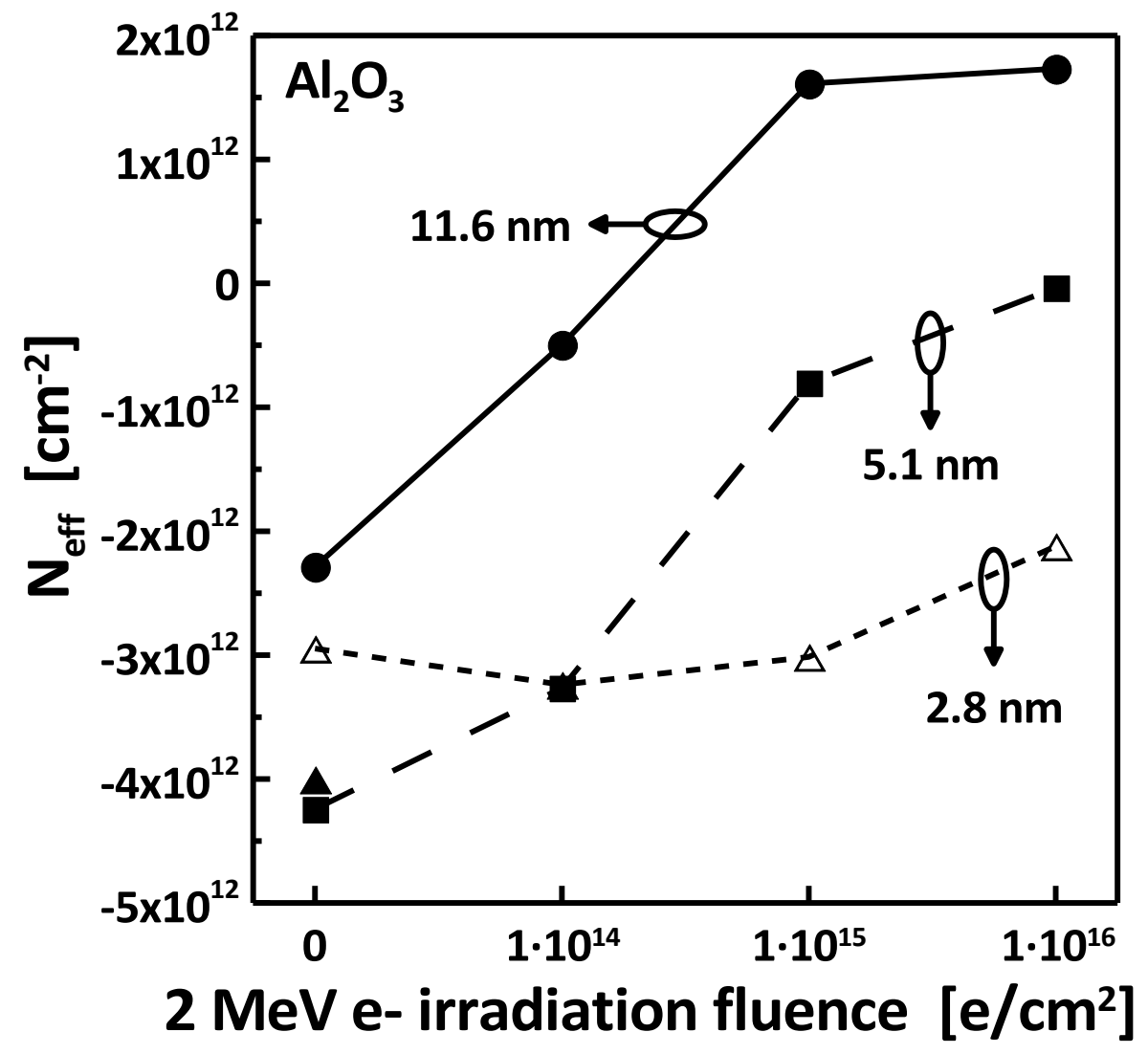

Figure 2 


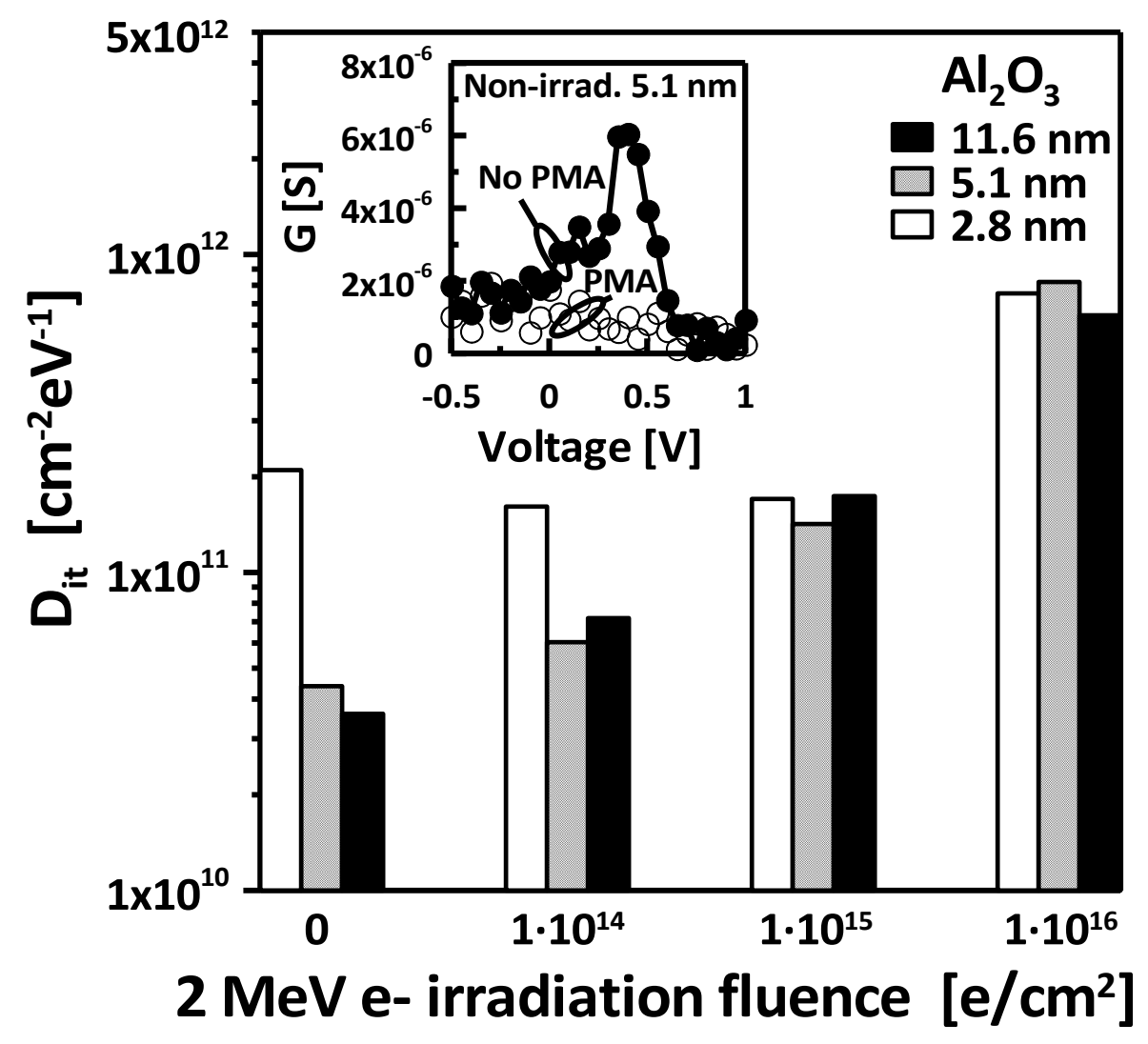

Figure 3 


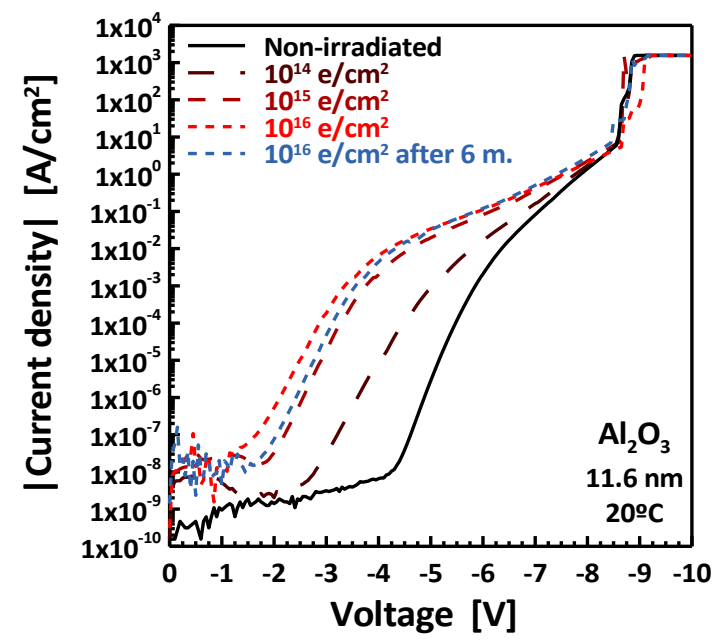

Figure 4(a)

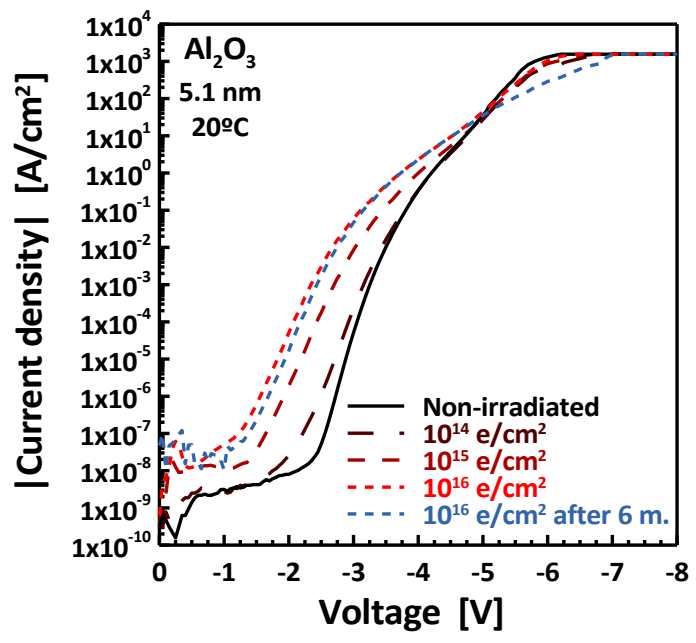

Figure $4(b)$

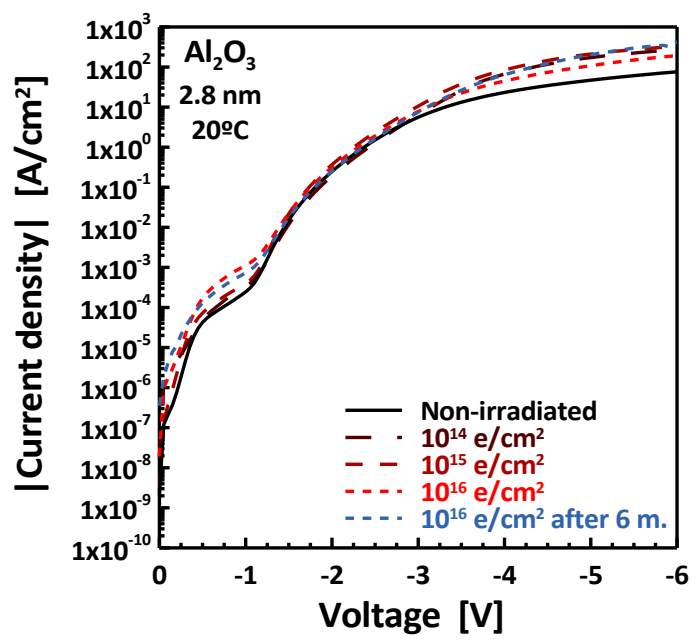

Figure $4(c)$ 


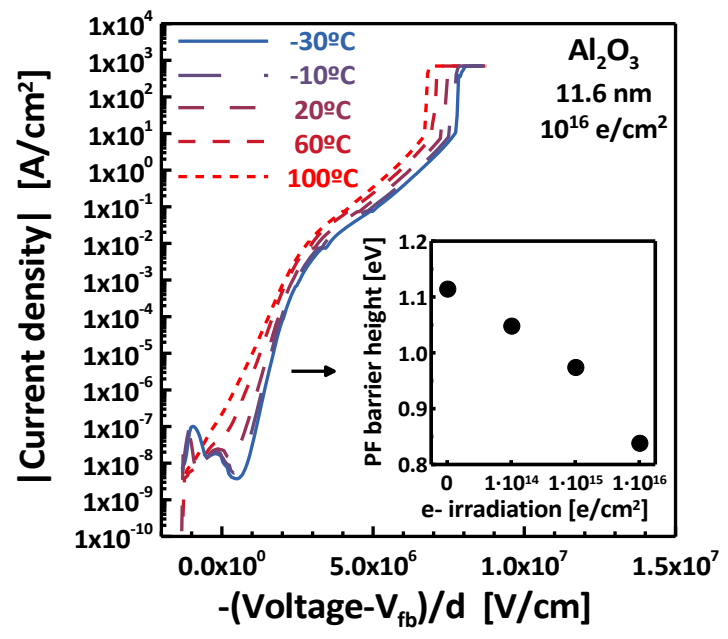

Figure 5(a)

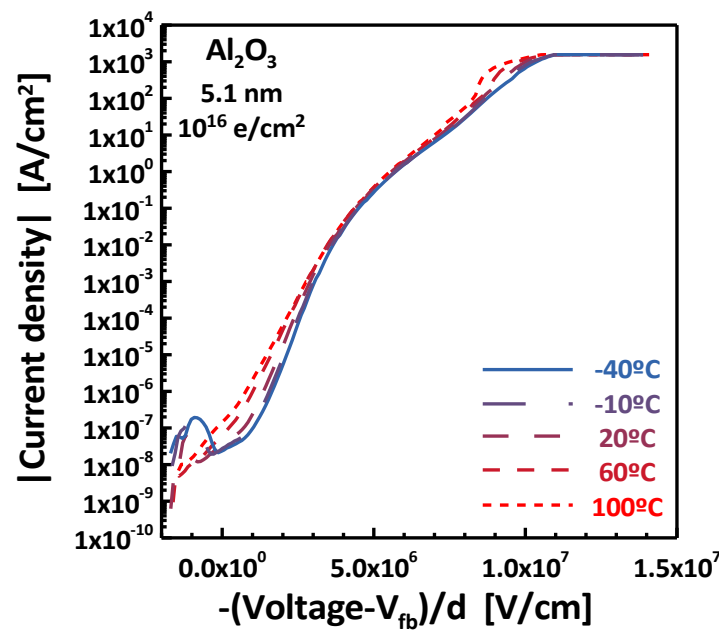

Figure 5(b)

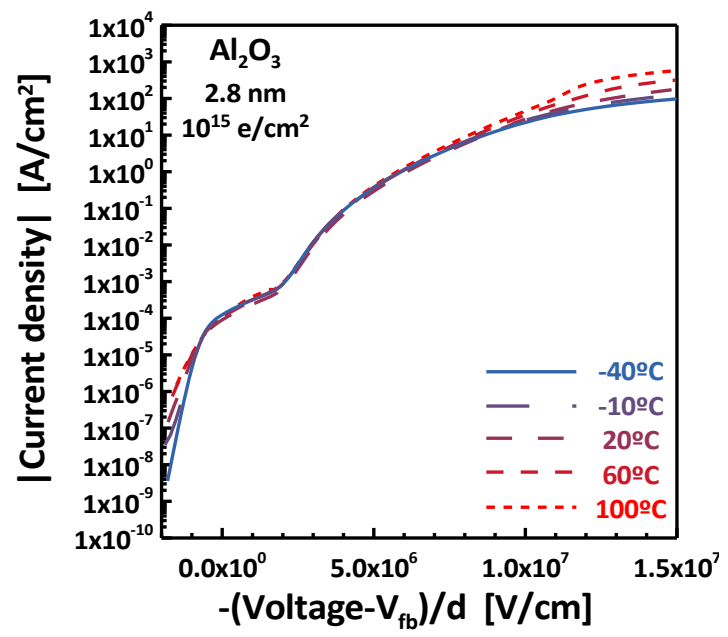

Figure 5(c) 